\title{
Micropropagation of walnut trees (Juglans regia $L$ ) and response to arbuscular mycorrhizal inoculation
}

\author{
R Dolcet-Sanjuan ${ }^{1 *}$, E Claveria ${ }^{1}$, A Camprubí ${ }^{2}$, V Estaún ${ }^{2}$, C Calvet ${ }^{2}$ \\ 1 Departament de Genètica Vegetal; \\ 2 Departament de Patologia Vegetal, Institut de Recerca i Tecnologia Agroalimentaries, \\ Centre de Cabrils, 08348 Cabrils (Barcelona), Spain
}

(Received 3 July 1996; accepted 23 September 1996)

\begin{abstract}
Summary - Juglans regia clones were micropropagated through the establishment of in vitro shoot-tip cultures and induction of adventitious roots. Shoot proliferation of juvenile $J$ regia material was higher than with clones established from adult trees. Genotype and juvenility of the plant material were determinant factors of the in vitro rooting ability. Rooting of adult $J$ regia clones was improved after rejuvenation by subsequent subcultures. The sucrose concentration in the root elongation medium affected the formation of secondary roots per rooted shoot and the acclimatization of plants. Mycorrhizal inoculation of micropropagated walnut trees improved post-acclimatization growth in greenhouse conditions. Inoculation with the arbuscular mycorrhizal fungi Glomus mosseae or $G$ intraradices significantly improved plant survival when transferred to nursery.
\end{abstract}

walnut / micropropagation / rooting / acclimatization / arbuscular mycorrhiza

\begin{abstract}
Résumé - Micropropagation du noyer (Juglans regia $L$ ) et effet de l'inoculation avec des champignons mycorhizogènes à arbuscules. Des clones de noyer, Juglans regia, ont été micropropagés via l'établissement de cultures in vitro d'extrémités de tiges et l'induction de racines adventives. La prolifération des tiges a été plus grande pour les clones juvéniles que pour les clones établis à partir d'arbres adultes. L'aptitude d'enracinement in vitro a varié avec le contexte génétique et le stade, juvénile ou adulte, du matériel de base. Le taux d'enracinement de clones adultes de $J$ regia a augmenté après rajeunissement du matériel au moyen de subcultures successives. La concentration de sucrose dans le milieu d'élongation des racines a eu un effet sur le nombre de racines formées et sur le sevrage des plantes. La mycorhization des noyers micropropagés a amélioré la croissance des plantes en serre. L'inoculation avec les deux champignons mycorhizogènes essayés: Glomus mosseae et Glomus intraradices a augmenté le taux de survie des noyers lors de leur transplantation en pépinière.
\end{abstract}

acclimatation / enracinement / micropropagation / mycorhizes à arbuscules / noyer

* Correspondence and reprints 


\section{INTRODUCTION}

The micropropagation of walnut trees presents some difficulties that have to be solved before this technology can be used as a commercial tool for clonal propagation of selected clones (McGranahan et al, 1987; Rodriguez et al, 1989; Gruselle and Boxus, 1990). The main difficulties are: i) the establishment of in vitro shoot-tip cultures from adult walnut trees, ii) uneven and low rates of multiplication or rooting and iii) high number of losses during acclimatization of plantlets to soil.

Walnut trees (Juglans nigra $\times J$ regia) were first micropropagated through in vitro culture of zygotic embryos and multiplication by shoot-tip cultures (Cornu and Jay-Allemand, 1989; JayAllemand et al, 1992). Explants from vigorously growing seedlings were used in the micropropagation of the walnut rootstock Paradox ( $J$ hindsii $x J$ regia) (Driver and Kuniyuki, 1984). However, little progress has been made in the micropropagation of adult walnut trees since the methodology published by McGranahan et al (1988). A modification of this methodology was used here to establish shoot-tip cultures and further micropropagate selected adult $J$ regia clones. The effects of rejuvenation and sucrose level on the in vitro rooting ability and acclimatization of $J$ regia clones were determined.

The use of micropropagation techniques where plants are grown under axenic conditions and then transplanted to sterile media, lacking arbuscular mycorrhizal (AM) fungi, do not allow the formation of the mycorrhizal symbiosis. During the first stages of growth the high nutrient levels of the potting media masks the mycorrhiza effect in many instances. However, some of the problems reported after field transplanting, like stunting and low survival rates, might be due to the lack of symbiosis. In this study the convenience of $A M$ inoculation to increase the survival and growth of $J$ regia plants after transfer to nursery was assessed.

\section{MATERIALS AND METHODS}

\section{Plant material}

Mature trees of the Juglans regia clones 'Serr' and 'MB-T-231' were selected for their characteristics as cultivars and rootstocks (Aletá and Ninot, 1993). Scions were collected and grafted on seedlings of the same species. Two to 3-year-old grafted trees, main- tained in a greenhouse to reduce the risk of in vitro contamination, were used as source of explants. Eight juvenile J regia clones ('SBE4', 'SBE5', 'SBE11', 'SBE15', 'SBE21', 'SBE22', 'SBE26', 'SBE27') were established from embryonic axis. Zygotic embryos originated from open pollinated crosses with 'MB-T$231^{\prime}$ as the maternal component.

\section{Medium and culture conditions}

After a preliminary comparison between DKW-C medium (McGranahan et al, 1987), MS medium (Murashige and Skoog, 1962) and woody plant medium (WPM) (Lloyd and McCown, 1980), the DKW medium (Driver and Kuniyuki, 1984) was chosen for the establishment and multiplication phases. This medium contained the original mineral nutrients, with $0.29 \%(w / v)$ Phytagel, and a $\mathrm{pH}$ of 5.5. Growth regulators ( $\mathrm{N}^{6}$-benzyladenine $[\mathrm{BA}]$ and indole-3-butyric acid [IBA] ) were added to the multiplication medium before autoclaving. In the root induction phase, $\alpha$-naphthaleneacetic acid (NAA) was dissolved in dimethyl sulfoxide (Dolcet-Sanjuan and Claveria, 1995) and added to the medium after autoclaving. During establishment, shoot multiplication and root elongation, all cultures were kept at $28^{\circ} \mathrm{C}$ under a photoperiod of $16 \mathrm{~h}$ of cool-white fluorescent light $\left(70 \mu \mathrm{mol} \mathrm{m} \mathrm{m}^{-2} \mathrm{~s}^{-1}\right)$. Root induction was performed in the dark

\section{Explant establishment and shoot multiplication}

Establishment of in vitro shoot-tip cultures from mature walnut trees was accomplished following the same methodology described for Pistacia vera L (DolcetSanjuan and Claveria, 1995) and walnut (McGranahan et al, 1988). Each explant was cultured in a tube containing $15 \mathrm{~mL}$ of DKW medium with $5 \mu \mathrm{M}$ BA and $0.05 \mu \mathrm{M}$ IBA. During the first 8 weeks, shoot-tip explants were subcultured weekly. Previous to their mass multiplication, apparently uncontaminated shoots were screened for bacterial contamination in plated 523 medium (Viss et al, 1991). Explants that showed bacterial growth on this medium were discarded. Depending on the genotype, branching and multiplication started between 3 to 9 months after initiation. For shoot multiplication, shoots or segments of at least $1 \mathrm{~cm}$ long were transferred every 4 weeks to flasks containing $100 \mathrm{~mL}$ of DKW medium supplemented with $5 \mu \mathrm{M} B A$ and $0.05 \mu \mathrm{M}$ IBA. Seven segments were transferred to each flask.

Juvenile $J$ regia clones were established from embryonic axes isolated and established in vitro as described by Jay-Allemand and Cornu (1986). After elimination of bacterial contaminated cultures and taking into account the in vitro multiplication and the rooting rates, following the methodology described by JayAllemand et al (1992), eight clones were selected and used in rooting and acclimatization trials. 


\section{Shoot multiplication experiments}

The effects of juvenility and genotype on the multiplication rates were studied. Shoot-tip cultures from eight embryo-derived $J$ regia clones and two mature $J$ regia clones ('Serr' and 'MB-T-231') were used. Each experiment consisted of a completely randomized design with ten replicate flasks containing five shoots each per clone. The multiplication rate was recorded, in ten consecutive subcultures (fifth to 15th), as number of shoots longer than $1 \mathrm{~cm}$ per cultured shoot after 4 weeks of culture.

\section{Rooting experiments}

A sequence of two rooting media, one with auxin and another with vermiculite (Jay-Allemand et al, 1992), was chosen for rooting assays. The rooting medium used was DKW (Driver and Kuniyuki, 1984) with onefourth the concentration of macronutrients and with no glutamine. Root induction was performed by culturing the shoots in the dark, for 5 days, in the rooting medium supplemented with $25 \mu \mathrm{M}$ IBA. Each flask contained $100 \mathrm{~mL}$ of medium and five shoots (3 to $5 \mathrm{~cm}$ long) taken from stock multiplication cultures. Root elongation was achieved after culture for 3 weeks in auxin-free medium and normal light conditions. The root elongation medium contained a $55 \%(\mathrm{v} / \mathrm{v})$ vermiculite $(250 \mathrm{~mL}$ vermiculite and $200 \mathrm{~mL}$ modified DKW medium per flask).

The in vitro rooting ability of eight juvenile clones ('SBE4', 'SBE5', 'SBE11', 'SBE15', 'SBE21', 'SBE22', 'SBE26', 'SBE27') and two mature clones ('Serr' and 'MB-T-231') was examined. Depending on the clone, shoots from the fifth to the 35th multiplication subculture were utilized. After root elongation the percentage of shoots forming roots was scored.

The beneficial effects of rejuvenation on rooting were determined by in vitro micrografting the mature $J$ regia 'Serr' on seedlings of the same species. Micrografts were performed with the help of a silicon tube to hold together scion and rootstock. When the scion was elongated enough, it was excised, subcultured and a second grafting was performed. Root induction was done in microcuttings derived from none, one or two micrografts. After root elongation the percentage of shoots forming roots was scored.

The effects of subsequent multiplication subcultures on rooting of mature ( $J$ regia 'Serr' and 'MB-T-231') or juvenile ('SBE11', 'SBE26', 'SBE27') clones were also studied. The number of subcultures in multiplication medium depended on the clone and ranged from six to 55 . The percentage of shoots forming roots was scored after root elongation.

The effects of three sucrose levels $(30,15$ and 0 $\mathrm{g} \cdot L$ ) on the root elongation of $J$ regia 'Serr' were evaluated. Shoots were grown for 5 days on the auxin-containing medium described earlier and then on auxin- free medium for 3 weeks. The percentage of shoots forming roots and the number of secondary roots per rooted shoot were scored.

For each experiment, three to five flasks with five shoots each were randomly selected for each treatment level. The results were analyzed statistically by analysis of variance and treatment means were compared by Fisher's least significant difference test and planned contrasts (Petersen, 1985).

\section{Acclimatization experiments}

Rooted plantlets were washed and potted in trays with $250 \mathrm{~mL}$ connical pots, containing steam-sterilized $\left(100{ }^{\circ} \mathrm{C}, 1 \mathrm{~h}\right)$ substrate (2 peat: 1 perlite, v/v). Plantlets were acclimatized for 3 weeks in plastic boxes. Two fungicide treatments (benomyl or captan) were applied during the first 2 weeks of acclimatization. They were gradually exposed to reduced relative humidity by progressively removing the box covers during the last week.

The effect of the sucrose level $(30,15$ and $0 \mathrm{~g} \cdot \mathrm{L})$ during the in vitro root elongation on the number of acclimatized $J$ regia 'Serr' plants was determined. Shoots were grown on auxin-containing medium for 5 days and then on auxin-free medium for 3 weeks. Four weeks after the acclimatization phase, the number of plants that developed new leaves and a root system was recorded and the percentage of acclimatization was calculated.

\section{Inoculation with AM fungi}

Four weeks after acclimatization, $J$ regia 'Serr' plants with new leaves and an extensive root system were repotted into $4 \mathrm{~L}$ polypropylene containers with a peat and sand mixture $(2: 1, v / v)$ and were inoculated with AM fungi. Inocula consisted of mixed soil and mycorrhizal roots of Allium porrum L. Plants colonized by Glomus mosseae (BEG12) (Nicol and Gerd) Gerdemann and Trappe or Glomus intraradices (BEG72) Schenck and Smith were grown on sandy soil. Each plant was inoculated with $10 \mathrm{~g}$ of the appropriate inoculum placed under the root system at the moment of planting. A filtrate of soil inoculum free from AM fungi was added to the control treatment. There were 30 plants per treatment. After 6 months' growth in a greenhouse, the plants were transferred to the nursery. The percentage of plant survival was assessed after 3 months field growth. Root samples were collected and stained with $0.05 \%$ trypan blue in lactic acid (Koske and Gemma, 1989), and the percentage of AM root colonization was determined using the grid-line intersect method (Giovannetti and Mosse, 1980). The percentage of plant survival after the transplant to nursery soil conditions was assessed after 3 months' growth. 


\section{RESULTS AND DISCUSSION}

\section{Explant establishment and shoot multiplication}

To reduce the risk of in vitro contamination, grafted trees maintained in the greenhouse were the best source of material for the establishment of shoot-tip cultures from field-grown, adult, selected trees. Most shoot-tip cultures established from cuttings or directly from field-grown trees were ruined by internal contamination of explants. Secretion of phenolics during the first days of culture was solved with frequent subcultures into fresh medium. In spite of this problem, establishment and multiplication of mature $J$ regia 'Serr' and 'MB-T-231' were successfully accomplished with the methodology described here. Juvenile $J$ regia clones, established from embryonic axes, presented less problems of contamination or secretion of phenolics during establishment than mature plant material. In addition, multiplication rates of mature $J$ regia shoot-tip cultures were satisfactory but never as high as those of some juvenile $J$ regia clones (fig 1 ). Significant differences on multiplication rates were also found among juvenile $J$ regia clones. Morphological differences such as apical dominance, axillary branching and leaf size were observed among embryo-derived $J$ regia clones. On the basis of

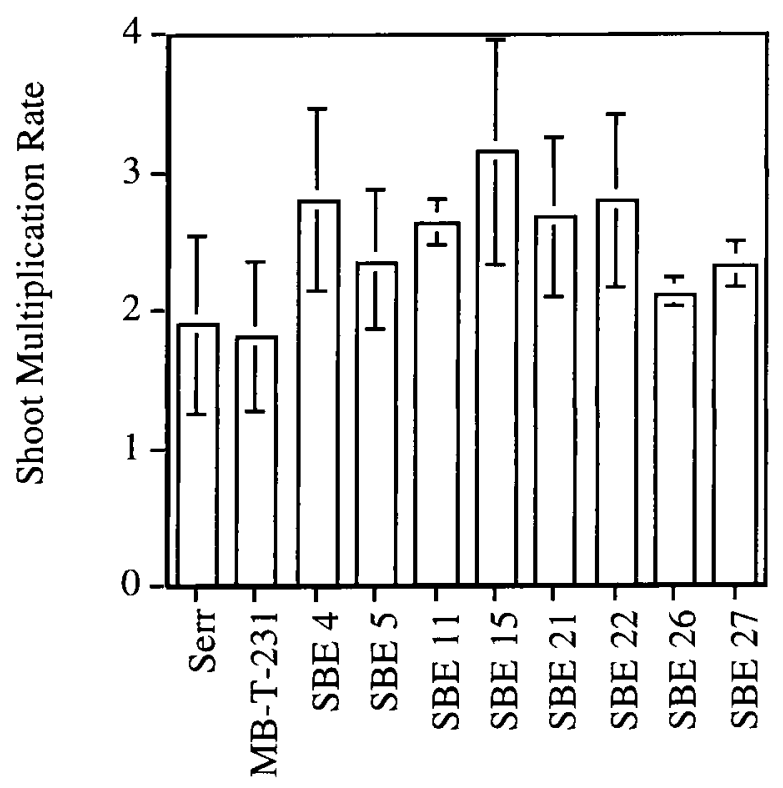

J. regia clone

Fig 1. In vitro shoot multiplication rates of mature ('Serr' and 'MB-T-231') and juvenile ('SBE4', 'SBE5', 'SBE11', 'SBE15', 'SBE21', 'SBE22', 'SBE26', 'SBE27') Juglans regia clones after five to 15 subcultures in multiplication medium. Vertical bars represent the standard error. these reported differences, three clones ('SBE11', 'SBE26' and 'SBE27') were selected and micropropagated for latter agronomic evaluation.

\section{Adventitious root formation}

The use of a vermiculite containing medium during the root elongation phase improved rooting of $J$ regia clones (Jay-Allemand et al, 1992). The number of roots, root elongation and formation of secondary roots was improved by the addition of vermiculite to the gelified medium. In these conditions, the formation of callus in the shoot base was reduced and a good vascular connection with the root system was found (Heloir et al, 1994).

Significant differences in root formation were observed among embryo-derived $J$ regia clones. Three of them, 'SBE11', 'SBE26' and 'SBE27', reached values from 25 to $40 \%$ of shoots forming roots. Higher rooting percentages were obtained with $J$ nigra $x J$ regia clones (Jay-Allemand et al, 1992) than with embryo-derived $J$ regia clones. In early stages of the multiplication phase (fifth to 35th subcultures), the percentage of shoots forming roots was lower for mature $J$ regia 'Serr' and 'MB-T-231' (12 and 5\%, respectively) than juvenile $J$ regia clones (fig 2). Large variations in the

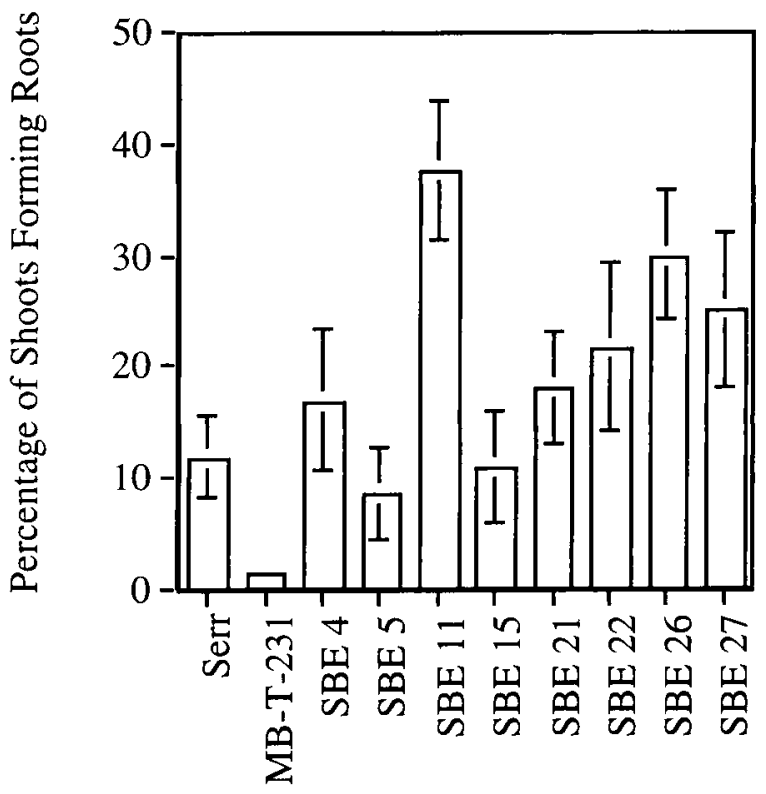

J. regia clones

Fig 2. Percentage of shoots forming roots in vitro from mature ('Serr' and 'MB-T-231') and juvenile ('SBE4', 'SBE5', 'SBE11', 'SBE15', 'SBE21', 'SBE22', 'SBE26', 'SBE27') Juglans regia clones after five to 35 subcultures in multiplication. Vertical bars represent the standard error. 
rooting aptitude were observed between successive subcultures. Selection of microcuttings during sequential rooting assays could be an explanation for these differences.

Embryo-derived clones showed good response to root induction even at early stages of multiplication. The number of subcultures in the multiplication medium progressively rejuvenated the plant material and also increased the rooting aptitude of the mature clones 'Serr' and 'MB-T231' (fig 3). However, more than 35 subcultures were necessary before $J$ regia 'Serr' reached a $40 \%$ rooting, similar to that obtained with $J$ regia embryo-derived clones only after five subcultures in the multiplication medium. With the objective of accelerating the rejuvenation process, $J$ regia 'Serr' derived from adult material was micrografted on shoots of embryo-derived cultures. The micrografting technique was successful; however, the percentage of rooting was not significantly increased after one or two successive micrografts (20 and $29 \%$, respectively) when compared with the rooting of no micrografted material (34\% of shoots forming roots).

The percentage of microcuttings forming roots as well as the number of primary roots per rooted shoot increased when the sucrose level in the root elongation medium was reduced from 30 to $15 \mathrm{~g} \bullet \mathrm{L}$ (Dolcet-Sanjuan et al, 1997). The beneficial effects of a lower sucrose level $(15 \mathrm{~g} \cdot \mathrm{L})$ were also found in the number of secondary roots per rooted shoot of $J$ regia 'Serr' (fig 4A). This characteristic was associated with a better acclimati-

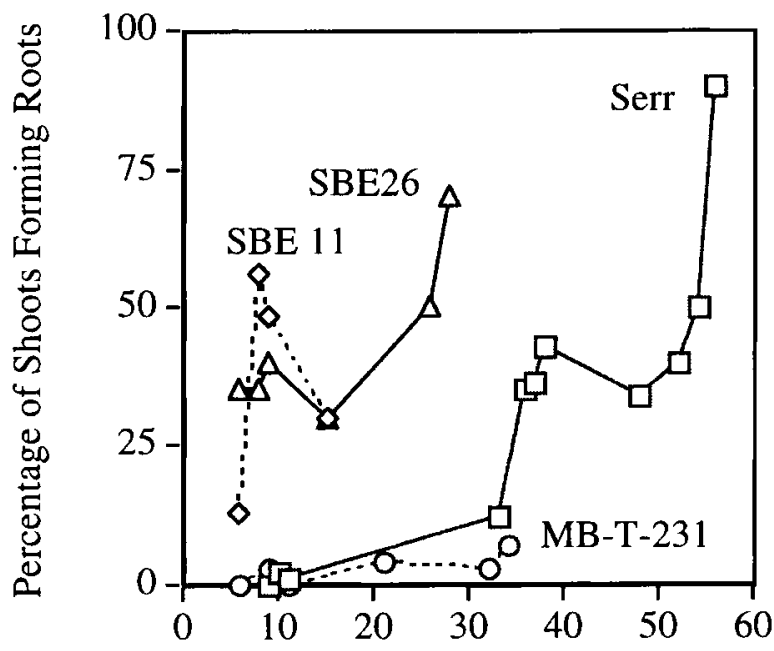

Subcultures in Multiplication Medium

Fig 3. Effect of the number of subcultures (six to 55 ) in multiplication medium on the percentage of shoots forming roots, with juvenile ('SBE 11' and 'SBE 26') or mature ('Serr' and 'MB-T-231') Juglans regia clones. Vertical bars represent the standard error. zation of plantlets to soil conditions when 0 or 15 $\mathrm{g} \bullet \mathrm{L}$ sucrose were added (fig 4B). However, $0 \mathrm{~g} \bullet \mathrm{L}$ sucrose had a lower percentage of rooting than $15 \mathrm{~g} \cdot \mathrm{L}$ (Dolcet-Sanjuan et al, 1997).

\section{Acclimatization of plantlets}

The percentage of acclimatized plants was genotype-dependent, $J$ regia clones being more easily adapted to soil conditions than $J$ nigra $x J$ regia hybrid clones (Frossard et al, 1997). Acclimatization assays were done with more than $800 \mathrm{~J}$ regia plantlets, which resulted in the survival of $25 \%$ of 'MB-T-231' and $83 \%$ of 'Serr' (out of 16 and 359 plantlets, respectively). Regardless of the genotype, the addition of vermiculite to the root elongation medium (Jay-Allemand et al, 1992; Heloir et al, 1994) favored the formation of primary and secondary roots. Moreover, lowering the sucrose content in the root elongation medium presumably stimulated the photosynthetic capacity, and consequently the survival of plantlets during acclimatization to soil was improved (fig 4). Acclimatized $J$ regia plantlets grown for over 1 month in a 2 peat: 1 perlite substrate produced some new leaves and an extensive root system, adequate for inoculation with AM fungi.

\section{AM fungi on plant survival}

Early AM inoculation of micropropagated $J$ regia 'Serr' trees improved the post-acclimatization

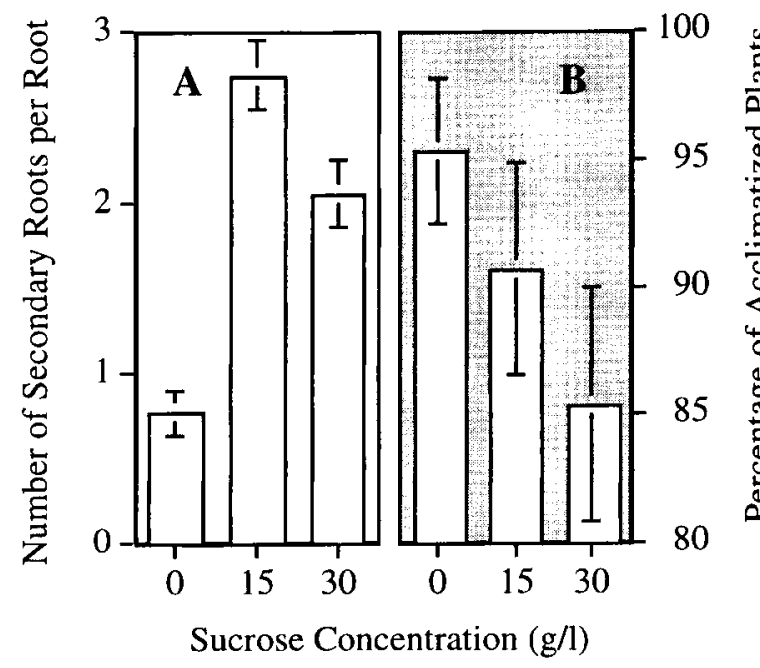

Fig 4. Effect of the sucrose concentration in the root elongation medium on $\mathbf{A}$ ) the number of secondary roots per primary root, and B) the percentage of acclimatized plants of Juglans regia clone ('Serr'). Vertical bars represent the standard error. 


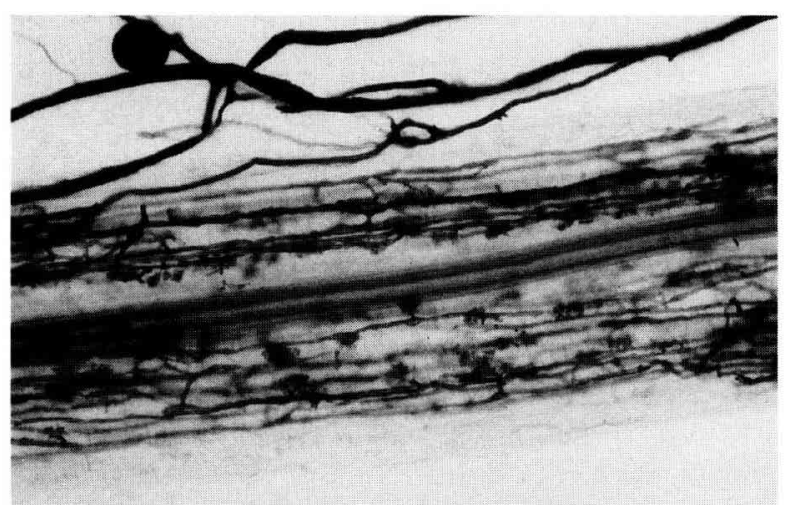

Fig 5. Roots of Juglans regia clone ('Serr') colonized with Glomus intraradices 6 months after inoculation. Samples stained with $0.05 \%$ trypan blue in lactic acid, and enlarged $x$ 50.

growth, in greenhouse conditions. Inoculation of $J$ regia 'Serr' with the AM fungi Glomus mosseae or $G$ intraradices significantly improved plant survival when transplanted to the field. Only $20 \%$ of the control plants survived while 60 and $80 \%$ of plants colonized with $G$ mosseae and $G$ intraradices, respectively, came through the transplant.

AM root colonization of micropropagated $J$ regia 'Serr' trees (fig 5) was $72 \pm 15 \%$ for $G$ mosseae, $73 \pm 11 \%$ for $G$ intraradices and $51 \pm$ $5 \%$ for uninoculated plants. Control treatments were colonized naturally after field transplanting, but the benefits of the colonization were observed only for the plants previously inoculated and transplanted with the symbiosis.

The results indicate that although AM fungi are present in the soil and the roots are eventually colonized with native endophytes, the early inoculation of micropropagated walnut plants with selected AM fungi confers protection against the stress situation due to the transplant process. The absence of AM fungi in the roots of micropropagated plantlets affects both survival and growth of micropropagated $J$ regia trees following their transfer to field conditions. Survival increase can justify the inoculation of in vitro propagated walnut plants with AM fungi in the early phases of plant growth after acclimatization.

\section{ACKNOWLEDGMENTS}

This work was supported by a grant from INIA (Instituto Nacional de Investigaciones Agrarias) and the AIR Program of the European Commission (CT920142). Use of trade names does not imply endorse- ment of the products named nor criticism of similar ones not named.

\section{REFERENCES}

Aletá N, Ninot A (1993) Exploration and evaluation of Spanish native walnut $(J$ regia $L)$ populations from catalonia and galicia. Acta Hort 311, 17

Cornu D, Jay-Allemand C (1989) Micropropagation of hybrid walnut trees (Juglans nigra $\mathrm{x}$ Juglans regia) through culture and multiplication of embryos. Ann Sci For 46, 113-116

Dolcet-Sanjuan R, Gruselle R, Jay-Allemand C, MeierDinkel A, Gaspar T (1997) Practical factors controlling in vitro adventitious root formation from walnut shoot microcuttings. In: European Development of Walnut Trees for Wood and Fruit Production as an Alternative and Extensive System to Agricultural Crops (C Jay-Allemand, ed), European Commission Directorate-General VI, Luxemburg (in press)

Dolcet-Sanjuan R, Claveria E (1995) Improved shoottip micropropagation of Pistacia vera $L$ and the beneficial effects of methyl jasmonate. J Am Soc Hort Sci 120, 938-942

Driver JA, Kuniyuki AH (1984) In vitro propagation of Paradox walnut rootstock. Hort Sci 19, 507-509

Frossard JS, Dolcet-Sanjuan R, Chenevard D, JayAllemand C (1997) Physiological aspects of microcuttings during acclimatization. In: European Development of Walnut Trees for Wood and Fruit Production as an Alternative and Extensive System to Agricultural Crops (C Jay-Allemand, ed), European Commission Directorate-General VI, Luxemburg (in press)

Giovannetti M, Mosse B (1980) An evaluation of techniques for measuring vesicular-arbuscular mycorrhizal infection in roots. New Phytol 84, 489-500

Gruselle R, Boxus P (1990) Walnut micropropagation. Acta Hort 284, 45-52

Heloir MC, Kevers C, Hausman JF, Deltour R, Gaspar T (1994) Histological origin of roots of micropropagated walnut (Juglans regia) shoots. Arch Int Physiol Biochim Biophys 102, PP5

Jay-Allemand C, Cornu D (1986) Culture in vitro d'embryons isolés de noyer commun (Juglans regia L). Ann Sci For 43, 189-198

Jay-Allemand C, Capelli P, Cornu D (1992) Root development of in vitro hybrid walnut microcuttings in a vermiculite-containing gelrite medium. Sci Hort 51, 335-342

Koske RE, Gemma JH (1989) A modified procedure for staining roots to detect VA mycorrhizas. Mycol Res 92, 486-505

Lloyd G, McCown B (1980) Commercially feasible micropropagation of mountain laurel, Kalmia latifolia, by use of shoot-tip culture. Proc Int Plant Prop Soc 30, 421-427 
McGranahan GH, Driver JA, Tulecke W (1987) Tissue culture of Juglans. In: Cell and Tissue Culture in Forestry, Case Histories: Gymnosperms, Angiosperms and Palms, Vol 3 (JM Bonga, DJ Durzan, eds), Martinus Nijhoff, Dordrecht, the Netherlands, 261-271

McGranahan G, Leslie CA, Driver JA (1988) In vitro propagation of mature persian walnut cultivars. Hort Sci 23, 220

Murashige T, Skoog F (1962) A revised medium for rapid growth and bioassays with tobacco tissue cultures. Physiol Plant 15, 473-497
Petersen RG (1985) Design and Analysis of Experiments, 1st edn. Marcel Dekker Inc, New York, NY, USA

Rodriguez R, Revilla A, Albuerne M, Perez C (1989) Walnut (Juglans spp). In: Biotechnology in Agriculture and Forestry, Vol 5, Tress II (YPS Bajaj, ed), Springer-Verlag, Berlin, Germany, 99-126

Viss PR, Brooks EM, Driver JA (1991) A simplified method for the control of bacterial contamination in a woody plant tissue culture. In Vitro Cell Dev Biol 27P, 42 